\title{
STUDENTS' COGNITIVE ANALYSIS USING RASCH MODELING AS AN ASSESSMENT FOR PLANNING OF STRATEGIES IN CHEMISTRY LEARNING
}

\author{
$\underline{\text { Rusmansyah and Almubarak }}$ \\ Chemistry Education, Faculty of Teacher Training and Education, University of Lambung Mangkurat \\ Jl. Brigjen H. Hasan Basri, Pangeran, Banjarmasin City, South Kalimantan 70123, Indonesia \\ *Correspondence: Telp : 0852-46329705, email: almubarak_kimia@ulm.ac.id \\ Received: March 31, 2020 \\ Accepted: November 29, 2020 \\ Online Published: December 31, 2020 \\ DOI : 10.20961/jkpk.v5i3.40936
}

\begin{abstract}
Rasch modelling based on assessment can help teachers analyze the students' cognitive knowledge level and development. However, teachers are considered unsuccessful in teaching where the achievement of indicators in learning science, such as chemistry, is not holistically actualized. This study aimed to analyze High School students' knowledge in Banjarmasin City, especially on students' knowledge (cognitive aspect), using the Rasch modelling data analysis technique and exploring how chemical learning strategies are planned based on the symptoms of the data obtained. The data collection technique used a dichotomous format test technique (multiple choices). The research method used was descriptive with a quantitative approach to examine Rasch's various data, which was then interpreted qualitatively to describe the issues raised. The study results show that person reliability (students) based on Rasch modelling analysis is +0.79 , and item reliability is +0.98 , where the value indicates that the consistency of the participant response pattern is "sufficient." Then, the mean person measure is -0.07 , while the mean item is 0.00 . It means that the participants' "mean value" is below the "mean value" of the item that the students' ability is below the item's ability. The Rasch data's recapitulation value showed that the response patterns of various data symptoms and those data were interpreted. It showed students' knowledge of atomic structure material was still considered low based on the Rasch model criteria. This is a reference for making appropriate chemical learning strategy plans to improve their knowledge. In conclusion, Rasch modelling-based assessment is effectively used in analyzing students' (cognitive) ability on atomic structure material. These results produce a strategic plan like what in chemistry learning such as the importance of conducting further diagnoses using misconception tests, identifying students' learning styles, constructing students' knowledge through the concept of chemical representation, and developing appropriate learning media according to their needs (students).
\end{abstract}

Keywords: students' cognitive, Rasch modelling, learning assessment, chemical learning

\section{INTRODUCTION}

Students' opinions already know before they have any learning experience, and that knowledge is known as "prejudice." [1]. The process of learning chemistry is a significant component in constructing their knowledge into scientific knowledge (scientific concepts). This knowledge construction process requires a cognitive conflict so that the students understand but can also interpret the phenomena they analyze [2-3]. Chemistry is closely related to phenomena and or human life, to be the basis of understanding in cognitive reinforcement, especially in learning chemistry. Understanding chemical-based phenomena 
could be taken with the students must have a representation mindset [4-5].

there needs to be a renewal in the chemistry learning process where the awakening does not only come for instructors and students. but also for other components such as the selection of learning media [2], [8], [9], learning style analysis [10,11,12], concepts basic chemistry learning is representationbased learning [13] - [17], and conducting learning assessments [18] - [25]. According to [1], students' structure and mental models that are not optimal make it difficult for them to understand and eventually experience misconceptions or do not understand the concepts given. However, the students' problematic dose of misunderstanding is difficult to change; it needs a specific approach to have a proper and scientific understanding [7]. This means that there needs to be a renewal in the chemistry learning process where resurrection does not only come for instructors and students. Many components contribute to the learning process of chemistry, such as the selection of learning media media [2], [8], [9], learning style analysis [10,11,12], the basic concept of chemistry learning, namely representation-based learning [13] - [17], and conducting learning assessments [18] - [25]..

The concept of representation is an inseparable part of chemistry learning [13], [15], [17], [26]-[28]. The students' understanding at the level of representation (macro, sub-micro, symbolic, visual, and mathematical) can help them improve their mental structure and models and motivation [29]. Besides, [1] also revealed that the dose

The Rasch modelling principle that each individual has the same chance or opportu- nity to answer one item correctly is similar when the students' ability is compared with the questions' level of difficulty [1] - [4]. In Rasch modelling, the students' knowledge is demonstrated through logit value, even [5] emphasized that Rasch modeling analyzes the students' ability and the ability of items, so the instruments used are valid and reliable in terms of measurement.

Then, previous study [22], [35], added that the validity and reliability of Rasch Model-based items could be used as reference material in the process of assessing students' abilities, especially in the analysis of cognitive structure which is evaluated as an indicator of academic achievement. the use of distractor in the diagnosis process based on Rasch is an appropriate way to analyze the development of the students' understandding [6], [7].

\section{METHODS}

Descriptive research is a study chosen using a quantitative approach [8] to determine the students' basic cognitive ability of atomic structure material, which is then analyzed using Rasch modelling [5]. The symptoms of Rasch modelling data are then interpreted and explained qualitatively to make the brought issues, which is cognitive analysis, can be narrated precisely and in detail.

In the Rasch Model, multiple-choice questions are called "Dichotomy," the cognitive test used was dichotomy format (multiple choices) with a total of 25 questions with atomic structure material. This multiplechoice question was taken from the book "High School Chemistry Problem Bank" with the assessment that the items presented are 
representative of the chemical material (atomic structure) so that this problem has the potential to be material for tests of knowledge analysis of samples [11]. The sampling technique used was purposive sampling, where the sample was taken through several considerations.

The sample used as the target of diagnosis is high school students in Banjarmasin. Students who have carried out previous tests so that the results of this analysis can be a reference material for teachers and researchers in the field of chemistry education to develop learning designs that suit their needs. The results of this Rasch data recapitulation are expected to be a guide for teachers, especially teachers at the high school level, to provide learning presentations according to their needs. What is needed here is like cognitive or thinking skills in learning chemistry, given the many paradigms built that chemistry is a difficult subject. Whereas according to [12], chemistry is an inseparable part of universal aspects, making it easier for participants to understand and interpret chemical materials.

The cognitive test with Rasch modelling is the second stage test. Where previously the same test had been carried out with a sample of 453 high school students, where this process used a test with the same multiple choice questions, in the topic atomic structure, and was distributed to 11 high schools in Banjarmasin, South Kalimantan. This second stage test is expected to obtain a concrete picture of the cognitive aspects of students. This explanation will make a teacher get an idea of developing students' thinking patterns towards chemistry.

The analysis begins by distributing the matter of the atomic structure's chemical value to 7 (seven) high schools in Banjarmasin with a total of 254 students. The data that has been adjusted to the Rasch model format is then analyzed using the WINSTEP Rasch modelling application. The various symptoms of Rasch modelling data are then interpreted and explained how their knowledge (students) about the chemical structure of the material. This analysis becomes a reference in making chemistry learning strategies in the classroom, concerning the importance of knowing their knowledge on a large scale. Symptoms of existing data will explain that if their experience is in the right criteria, what learning strategies should be planned to increase brand knowledge and vice versa.

\section{RESULTS AND DISCUSSION}

The exposure of the below Rasch model data variety is considered representative to show how students' response pattern to the atomic structure material. This Rasch model data can be an evaluation material for teachers to examine how the students' learning progress and what strategies are needed so that future chemistry learning will have better quality. The result of the Rasch data disclosed is part of renewal in improving the quality of chemistry learning, especially the quality of thinking of the students.

The picture below is a maps variable which shows the comparison of ability between items and students. On the right side is the "item" sign or distributed question, while on the left side is the "person" or student who responds to the item. The maps variable shows that the position of the item is above the rank of the person. That means 
that the initial analysis shows that the student's ability is below the ability of the question, which is then strengthened by other data in Rasch modelling. Code "x," which is lined up as "xxxxxxx," means that some students have the same ability so that in logit value, they have the same capacity ( $\mathrm{x}=$ one student). Then, 158LE code (students) is a student who has the with compared to other students with a logit value of 2.63 , while 183PE has a logit value of 2.15 . On the other hand, P22 code (item/question) is a question that has the highest level of difficulty with a logit value of 3.10 then P19 with a logit value of 2.97 .

Related to the above analysis, the personal code of 032PA with a logit value of 5.00 is the student who has the lowest ability among other students. While the code item of P5 (item) with a logit value of -2.47 is the question that has the lowest level of difficulty or it can be said that the question of P5 is the question that is most easily responded/answered by the respondents, in this case, the students. Visualization of maps variable can be an initial benchmark for teachers to track how far the students' understanding in responding to the questions given. In this case, the researcher distributed the atomic structure material questions as a basis for analysis related to high school students' cognitive development in the city of Banjarmasin. This question's distribution has been done before to the students and with the same data analysis technique, namely the Rasch model. Uniquely, the Rasch modelling analysis results showed that the questions with the highest level of difficulty were P22 and P19. It means that both college students and high school students have a problem simultaneously; thus, this can be an evaluation of the teacher designing a teaching strategy that emphasizes the case problems described.

Rasch modelling analysis on college students shows that the students have the ability above items/questions. It seems reasonable concerning the psychological, mental, and thinking ability aspects of college students, which are considered more mature than high school students. Other comparisons such as learners with code of 069PC 071PC 073PC 078PC 097PC 099LC 141PD 153LE 164LE 168LE 175PE 192PF 193PF 195PF 210LF 211LF 219PG 220PG 221PG 225LG 226LG 236PG 237PG 238LG 239PG are learners who have ability equal to the logit value of 1,13 .

Overall, based on map variable data, each student has a variety of abilities in responding to a given problem, and or even most students have the same ability to respond. The maps variable is not the only one full reference related to the analysis of the students' cognitive ability in the atomic structure's chemistry material.

Figure 1 is the "maps variable" of Rasch modelling or known as "wright map." A variable map is a map that illustrates the distribution of students/respondents' ability data and the level of difficulty of the distributed questions. The Wright map on the left demonstrates the learners' ability in which the map's symptoms become a reference in describing students' knowledge in responding to distributed questions.

The right side is an item or question with code P22, where it has a logit value of 
3.10 and P19 with a logit value of 2.97. The item shown in Figure 1 is the item with the highest difficulty level based on the result of the Rasch analysis. Then, the left side is the students' code such as 158LE with a logit value of 2.63 and 183PE with a logit value of

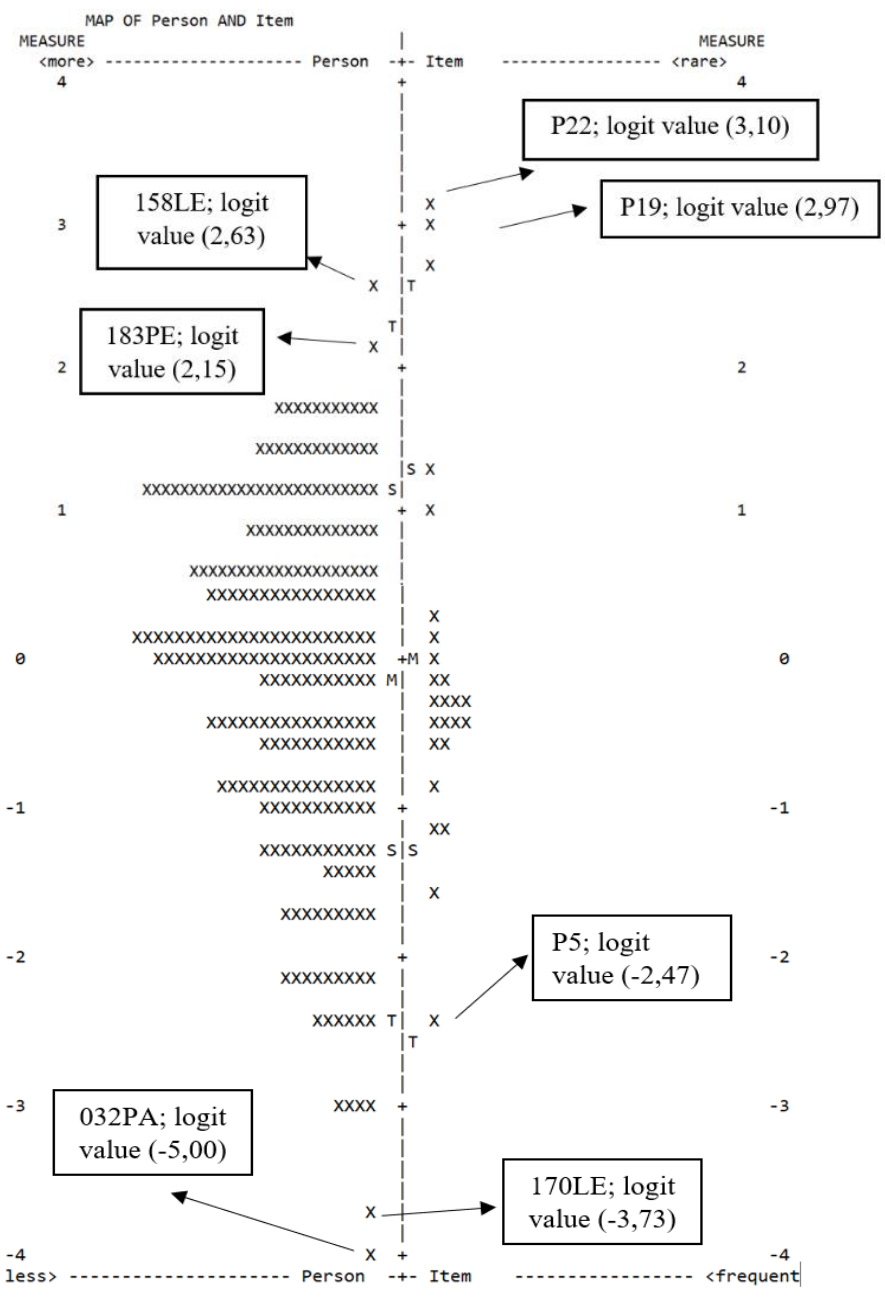

Figure 1. Description of the Rasch Maps Variable Data Model

If Figure 1 shows that the students' ability is below the items' ability, then the following is a person fit data from Rasch modeling. This person fits maps the ability of the students according to achievement grouping interest. Rasch modelling can also detect if it is found any participant or sample in which his/her response pattern does not match. The intended different response pattern is that the participant experiences a discrepancy with
2.15, where participants with that codes are students who have the highest ability or answer the most items so that they are judged (158LE \& 183PE) to have a good understanding related material. 
Person not fit $\mathbf{0}$ Person fit

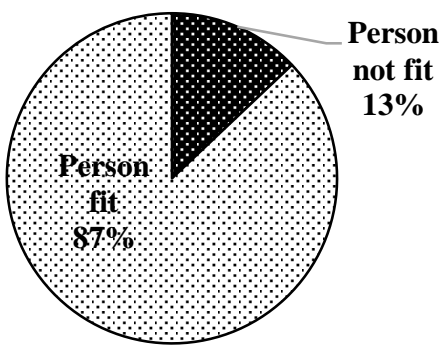

Figure 2. The percentage of suitability and misfit of the sample with the model (outlier or misfit).

The criteria used to check the suitability of the samples that do not fit the model (outlier or misfit) [5]. The Rasch modelling data's usefulness with predetermined criteria indicates that the data is declared according to the standard of analysis and value criteria range. Otherwise, the participant is judged to have the difference between the pattern of responses and their ability. The following are the intended criteria [5] ; a Received value of Outfit Mean Square (MNSQ): $0.5<$ MNSQ <
1.5; Received value of Outfit ZStandard (ZSTD): $-2.0+2.0<$ ZSTD <; Value of Point Correlation Measure (Pt Mean Corr): $0.4<$ Pt Mean Corr $<0.85$.

Figure 2 shows that $13 \%$ of participants experiencing mismatches or not fit from the total sample $(n=255)$. It means that there are participants whose response patterns are not fit, namely in 002LA, 110PC, 043PB, 003LA, and 065PB modes. These modes are students who are considered not fit. However, many students are experiencing a mismatch (not fit) to become part of developing an instructional design. They are declared to be not fit because they have a means-square outfit (MNSQ), z-std outfit (ZSTD), and point measure correlation that is off from the allowed limit (see person fit criteria). Figure 3 shows the statistical value of the person fit of students rated as having misfit or not fit.

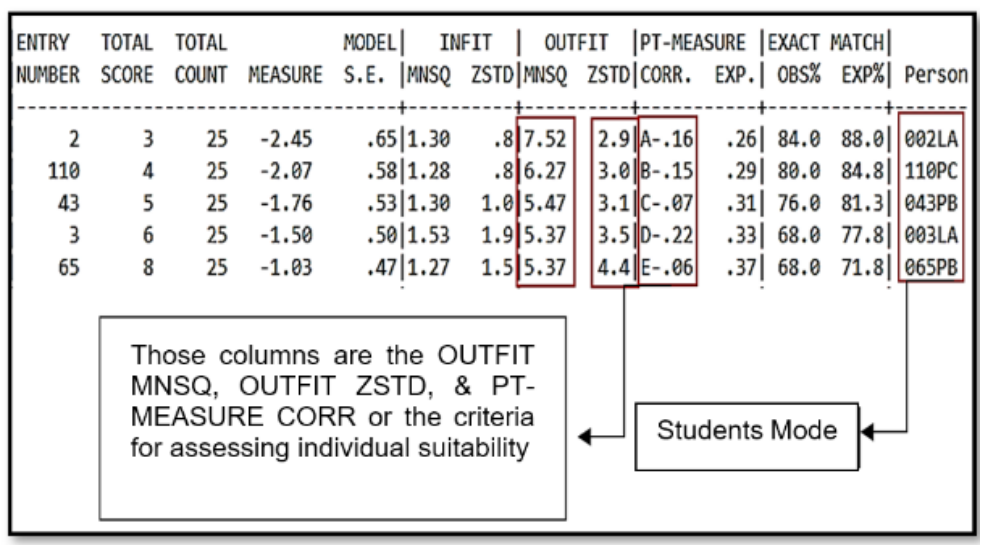

Figure 3. Rasch data of students on "Person fit."
Analysis in the context of person fit is constructive for teachers in accurately detecting each individual's weaknesses and the location of these weaknesses; therefore, Rasch modelling can be an initial strategy in the fundamental reading process of the students' cognitive. The person or participant who is previously rated as misfit is concluded that they had an unusual response pattern, 
which is related to their knowledge of chemical material. Even though participants were not fit/misfit, the misfit person's data also shows that many were judged to be fit or had provided appropriate response patterns and were following the model.

That can be seen based on Figure 4, where the graph showing the percentage of person fit from overall Rasch statistical data. Even though the "outfit zstd" criteria indicate that there was only $8.23 \%$ of participants who were fit for the requirements, but the "pt-measure corr" and "outfit mnsq" criteria, there were respectively $26.67 \%$ and $12.94 \%$ for each standard. It means that some participants were considered to be still fit from all responses or had the right consistency in responding to the distributed items.

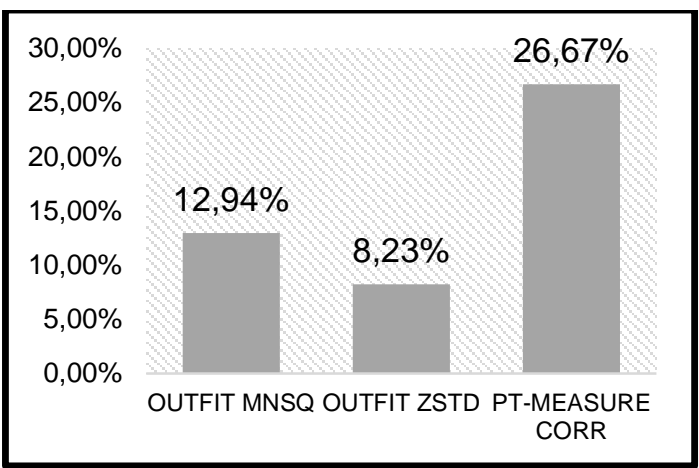

Figure 4. Data Percentage of Rasch Modeling "Person Fit"

\section{GUTTMAN SCALOGRAM OF RESPONSES: \\ Person---Items \\ $211 \quad 1221211121 \quad 112$ \\ 5911407342345607123586892 \\ $+1100001100000001010000011065 \mathrm{~PB}$ $+0000010010001000000110001003 \mathrm{LA}$ $+0100001000001000000100010043 \mathrm{~PB}$ $+0011000000000000000001100110 \mathrm{PC}$ $+0000100000000000010000100002 \mathrm{LA}$}

Figure 5. Response Pattern based on Scalogram
The designation of the value above (figure 4) can be dissected through a scalogram (see figure 5). A scalogram's benefit is detecting fraud, where the students with their response patterns are considered to be not careful, to cheat, or to guess [44]. Focus on the pattern of the student's response with code 065PB; the student with 065PB code only answered correctly for a total of 8 (eight) items out of 25 items distributed. Suppose the order of the item difficulty level is getting to the right side. In that case, the item has a high level of difficulty, so the item of 22 and 19 are the most difficult items (based on the distribution of Rasch modelling data).

065PB student has an irregular pattern in responding as well as participants of 003LA, 043PB, etc. Focus that the most challenging question (item 22), the 065PB participant responded, or he/she answered correctly and item of 19 , but in item 18,06 , etc. (0 patterned), 065PB is incorrect in answering those items. It means that 065PB experienced cognitive inconsistencies related to the atomic structure material. The atomic structure material is the primary material studied at the high school level, so this case needs to consider and evaluate material for the teachers. The 065PB analysis is a description of how to analyze the next participant, which is a response pattern experiencing inconsistency, and this is an essential part of the action.

Look at Figure 6, where item number 14 in Rasch data is included in item number 5 , which has a level of difficulty that is judged to be lower than the item being seen (see figure 5). The participant with 065PB code did not correctly answer item number 14 , but 
065PB correctly answered/responded to item number 19 , where this item has the highest level of difficulty compared to item 14 . Then, the context of questions number 14 and 19 were similar, which is about the orbital concept. Logically, if the participant correctly answers item number 19, then 065PB should correctly answer item number 14 . It means that the 065PB's response is judged to be cognitively confusing and unscientific.

065PB did likely "guessing" by paying attention to the pattern of responses provided and many questions that responded inconsistently. This is a part of early detection related to the students' cognitive. It is also because item number 14 is a fundamental concept in interpreting and identifying electrons in the orbital filling. When the number of 19 is declared correct (response from 065PB) but the idea of orbital as in item number 14 is responded to wrongly, then 065PB has a structure and mental model that is not appropriate for understanding the temporal context specifically related to the questions discussed.

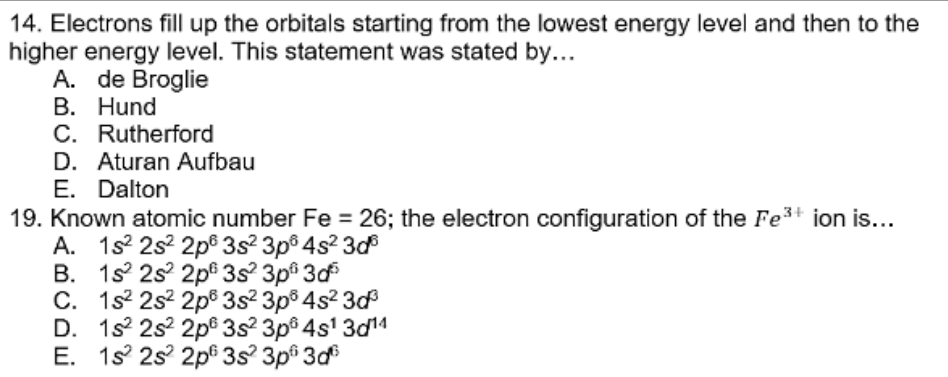

Figure 6. Description of items number 14 and 19

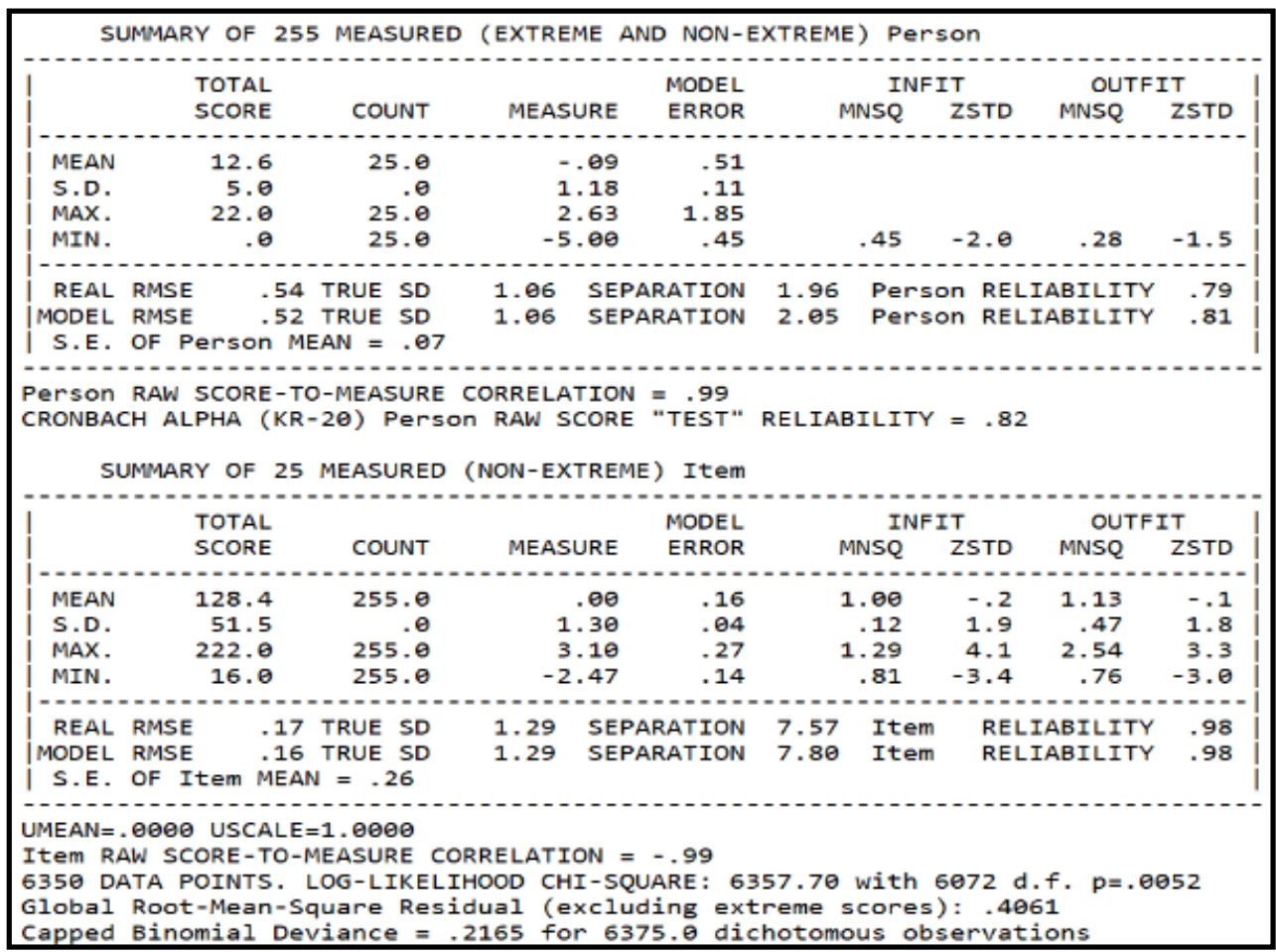

Figure 7. Summary of Rasch Modeling Statistics 
The statistical summary is comprehendsive information about the quality of participants' response patterns, instrument quality, and person fit. The statistical data below shows that the mean person measure is amounted to -0.07 , while the mean item is $0: 00$. It means that the participants' "mean value" is below the items' "mean value" that the students' ability is below the items' ability. Then, the alpha Cronbach value, which aims to find out the interaction between person and item as a whole, had a value of 0.82 ; if seeing the criteria for alpha Cronbach, the score is in the criteria of "Good."

The person reliability value gained is +0.79 , and the item reliability is +0.98 , in which the matter indicates that the consistency of the participants' response patterns is "enough." In contrast, the quality of test items in its reliability aspect instrument is classified as "special" [5]. The cognitive structure of the participants is considered acceptable in responding to the variety of questions distributed. This result almost has the same characteristics when this cognitive test is distributed to college students who assumed they (students) could answer or respond to questions correctly. Still, they have the reliability or ability to answer questions in weak criteria (person reliability is 0.00 , and item reliability is 0.89 ). It means that the students are under the command of the problems. In terms of education, college students should have a better and more appropriate response because they have experienced various learning experiences with many types of Subjects (MK) in the classroom and even theory proofing in the laboratory.
Overall cognitive analysis based on Rasch modelling data shows a need for renewal in learning chemistry. Research using the Rasch model is an alternative way to analyze how far the students' abilities in understanding phenomena [5], [15], [16]. The Rasch model does not only analyze from the cognitive aspects of the knowledge of students, but Rasch modelling also helps in detecting the appropriateness of instruments that are being used as measuring instruments such as multiple choices cognitive tests, essays, etc. [3], [16]-[19].

Statistical data shown by Rasch modeling helps the researcher map and interpret numbers based on the data's symptoms shown [20]. In fact, [21] have made an update by developing an instrument based on computer modelling with Rasch's approach to assessing the students' conceptual ability. This research results in a manifestation that assessing students' knowledge can use the strategy described.

Related to the explanation above, the recapitulation of the Rasch model data obtained shows that the teachers need to do various strategies in chemistry learning, especially in atomic structure material. The first strategy is for the teachers to analyze or retest the students through a test based on a misconception [22].

Besides, [22] also added that the teachers are prohibited from having an understanding that each participant has "zeroknowledge" before they understand a context of phenomena; it means that each student already has knowledge called "pre-concepts." Therefore, the teachers need to construct this knowledge into "scientific concepts." 
In the second strategy, the teachers identify the students' learning styles. Each individual has their respective characteristics, so it needs to be known precisely related to their learning styles, especially prospective teachers [23]. Moreover, learning style and cognitive are mutually influential units because each experiences various transformations, including incidents and perspective changes, so they tend to have different learning needs [24]. Multiple intelligences are one of the learning styles used as an indicator by teachers to determine each participant's strengths and weaknesses [25].

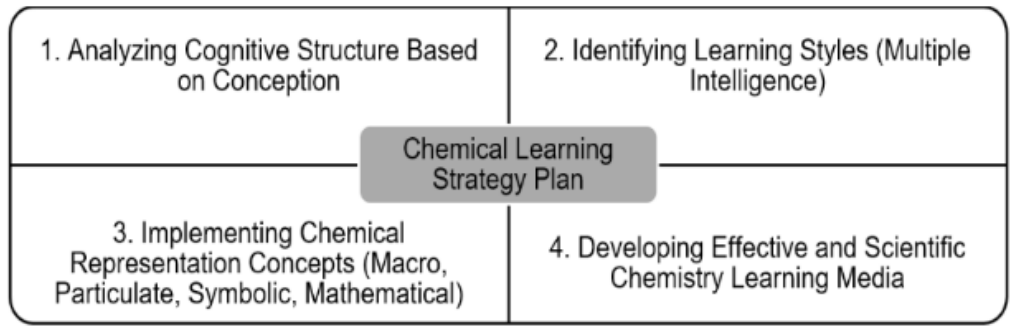

Figure 8. Planning of Strategies in Chemistry Learning according to Research Results

The third strategy is applying representation-based chemistry learning because representation is an appropriate concept in understanding chemical material [26]-[29]. Assessed, as a very suitable concept [12], it reinforces that learning chemistry with the idea of representation, especially the sub-microscopic level, will help the students interpret a phenomenon scientifically. Although [30] said that the concept of multi-representation is a difficult concept to learn, [31], [32] assessed that with the understanding of multi-representation, each participant could understand in-depth and scientifically about chemical material, which is then related to the context of life.

The statement above is closely related to the study of data on Rasch's data item number 19 , where participants need to understand the concept of orbital precisely according to theory so that they are not flawed in understanding the context of the material. It means that understanding related to the orbital idea is a part of their ability to understand electrons, configurations, bonds, atomic concepts, etc., in representation.

The fourth strategy is to develop chemical learning media such as teaching materials, technology media, and modules as supplements or supports in the learning process. According to [33], textbooks or teaching materials are traditional media often used in the school environment. The development of learning media needs to adjust to the students' learning needs, so the media is a product of development and can also motivate learning participants [33].

That is, instructional media is not oriented on the product or media, but how far the media influences and changes the students' perspective scientifically [33]-[35]. In addition to simplifying the learning process, [36] stated that learning media could effectively increase the participants' understanding of learning. [37] reinforced that the implementation of media can stimulate mindset, emotion, attention, and attractiveness of each person, so this can be the primary 
thought that the media is a significant part of chemistry learning.

Overall this research illustrates that using Rasch modelling to analyze the learners' knowledge is an alternative method that can be used by teachers or even lecturers as a reference in carrying out teaching. Knowing the level of their ability (the students) is necessary to know and understand how far the students' progress of learning and knowledge. Symptoms of the data presented by various types of Rasch modelling data add to the accuracy that the Rasch model is appropriate to know how far the students' chemical knowledge through the different data patterns of the Rasch model.

Rasch's statistical data shows that the students' ability is below the "sufficient" category's capacity. It means that increasing the students' knowledge through chemistry learning appropriate to needs and learning styles is needed. Based on Rasch's analysis, overall, it is essential to plan a chemistry learning strategy according to Figure 8, where the plan is expected to accommodate the students' learning problems fully.

\section{CONCLUSION}

Cognitive analysis using Rasch modeling is an appropriate form of assessment to make teachers understand how far the students' mental development at the High School level in Banjarmasin City, especially in the material taught in Chemistry. Overall, statistical data with Rasch modelling shows that person reliability (student) based on Rasch modelling analysis is +0.79 , and item reliability is +0.98 , where the value indicates the participants' consistency. response pattern is "sufficient."
Then, the mean person measure is -0.07 , while the mean item is 0.00 . It means that the participants' "mean value" is below the "mean value" of the items/questions; thus, the students' ability is below the items' ability. In conclusion, assessment based on Rasch modelling effecttively analyzes students' (cognitive) knowledge of atomic structure material. This result produces chemical learning strategies that are, 1) the importance of conducting further diagnoses using misconception tests, 2) identifying students' learning styles, 3) constructing students' knowledge through the concept of chemical representation, and 4) developing appropriate learning media according to their needs (students).

\section{REFERENCES}

[1] P. Johnson, "Una progresión de aprendizaje para la comprensión del cambio químico," Educ. Quim., vol. 24, no. 4, pp. 365-372, 2013.

Google Scholar

[2] M. P. Rabbitt, "Causal inference with latent variables from the Rasch model as outcomes," Meas. J. Int. Meas. Confed., vol. 120, no. February, pp. 193-205, 2018.

DOI: 10.1016/j.measurement.2018.01.044

[3] J. Runnels, "Using the Rash model to validate a multiple-choice English achievement test," Int. J. Lang. Stud., vol. 6, no. 4, pp. 141-155, 2012.

Google Scholar

[4] A. M. Talib, F. O. Alomary, and H. F. Alwadi, "Assessment of Student Performance for Course Examination Using Rasch Measurement Model: A Case Study of Information Technology Fundamentals Course," Educ. Res. Int., vol. 2018, pp. 1-8, 2018.

DOI:10.1155/2018/8719012 
[5] B. Sumintono and W. Widhiarso, Aplikasi Pemodelan Rasch Pada Assessment Pendidikan. Cimahi: Penerbit Trim Komunikata, 2015. Google Scholar

[6] J. de la Torre, "A Cognitive Diagnosis Model for Cognitively Based MultipleChoice Options," Appl. Psychol. Meas., vol. 33, no. 3, pp. 163-183, 2009.

DOI:10.1177/0146621608320523

[7] C. F. Herrmann-Abell and G. E. DeBoer, "Using distractor-driven standards-based multiple-choice assessments and Rasch modelling to investigate hierarchies of chemistry misconceptions and detect structural problems with individual items," Chem. Educ. Res. Pract., vol. 12, no. 2, pp. 184-192, 2011.

DOI: 10.1039/C1RP90023D

[8] J. Creswell, Research Design: Qualitative, Quantitative, and Mixed Methods Approaches, 3rd ed. California, USA: SAGE Publications, Inc, 2009. ISBN: 9781506386706

[9] S. W. Chan, Z. Ismail, and B. Sumintono, "A Rasch Model Analysis on Secondary Students' Statistical Reasoning Ability in Descriptive Statistics," Procedia - Soc. Behav. Sci., vol. 129, pp. 133-139, 2014.

DOI: 10.1016/j.sbspro.2014.03.658

[10] B. Sumintono, "Rasch Model Measurements as Tools in Assessment for Learning," no. October 2017, 2018. Google Scholar

[11] R. R. Melati and D. Kurniawati, Bank Soal Kimia SMA/MA. Surakarta: PT Aksarra Sinergi Media, 2012.

Google Scholar

[12] J. K. Gilbert and D. F. Treagust, "Introduction: Macro, Submicro, and Symbolic Representations and the Relationship Between Them: Key
Models in Chemical Education," in Multiple Representations in Chemical Education, Models and Modeling in Science Education, Berlin, Heidelberg: Springer Science + Business, 2009, pp. 1-8.

DOI: 10.1007/978-1-4020-8872-8_1

[13] M. Walpuski, M. Ropohl, and E. Sumfleth, "Students' knowledge about chemical reactions - development and analysis of standard-based test items," Chem. Educ. Res. Pract., vol. 12, no. 2, pp. 174-183, 2011.

DOI: 10.1039/C1RP90022F

[14] X. Liu, "Difficulties of items related to energy and matter: Implications for learning progression in high school chemistry," Educ. Química, vol. 24, no. 4, pp. 416-422, 2015.

DOI: $10.1016 / S 0187-893 X(13) 72495-9$

[15] M. Park, X. Liu, and N. Waight, "Development of the Connected Chemistry as Formative Assessment Pedagogy for High School Chemistry Teaching," J. Chem. Educ., vol. 94, no. 3, pp. 273-281, 2017.

DOI: 10.1021/acs.jchemed.6b00299

[16] T. P. Yamato, C. G. Maher, B. T. Saragiotto, M. J. Catley, and A. M. Moseley, "Rasch analysis suggested that items from the template for intervention description and replication (TIDieR) checklist can be summed to create a score," J. Clin. Epidemiol., vol. 101, pp. 28-34, 2018.

DOI: 10.1016/j.jclinepi.2018.05.014

[17] H. S. Lee, O. L. Liu, and M. C. Linn, "Validating measurement of knowledge integration in science using multiple-choice and explanation items," Appl. Meas. Educ., vol. 24, no. 2, pp. 115-136, 2011.

DOI: 10.1080/08957347.2011.554604

[18] A. G. Murray and B. F. Mills, "An application of dichotomous and 
polytomous Rasch models for scoring energy insecurity," Energy Policy, vol. 51, pp. 946-956, 2012.

DOI: 10.1016/j.enpol.2012.09.070

[19] R. M. Yasin, R. C. Rus, A. Ahmad, M. B. Rahim, and F. A. N. Yunus, "Validity and Reliability Learning Transfer Item Using Rasch Measurement Model," Procedia - Soc. Behav. Sci., vol. 204, no. November 2014, pp. 212-217, 2015.

DOI: 10.1016/j.sbspro.2015.08.143

[20] W. J. Boone, "Rasch analysis for instrument development: Why, when, and how?," CBE Life Sci. Educ., vol. 15, no. 4, 2016.

DOI: $10.1187 /$ cbe. $16-04-0148$

[21] S. Wei, X. Liu, Z. Wang, and X. Wang, "Using Rasch measurement to develop a computer modelling-based instrument to assess students' conceptual understanding of matter," J. Chem. Educ., vol. 89, no. 3, pp. 335-345, 2012.

DOI: $10.1021 / \mathrm{ed} 100852 \mathrm{t}$

[22] H. D. Barke, A. Hazari, and S. Yitbarek, Misconceptions in Chemistry (Addressing Perceptions in Chemical Education). Berlin, Heidelberg: Sense Publisher, 2009.

DOI: 10.1007/978-3-540-70989-3

[23] Ö. Ö. Oskay, E. Erdem, B. Akkoyunlu, and A. Yolmaz, "Prospective chemistry teachers' learning styles and learning preferences," in WCES-2010, vol. 2, no. 2, pp. 1362-1367, 2010.

DOI:10.1016/j.sbspro.2010.03.201

[24] J. Mezirow, Transformative Dimensions of Adult Learning. San Francisco: Jossey-Bass, 1991. ISBN: 978-1-555-42339-1

[25] S. Şener and A. Çokçalışkan, "An Investigation between Multiple Intelligences and Learning Styles," J.
Educ. Train. Stud., vol. 6, no. 2, p. 125, 2018.

DOI: 10.11114/jets.v6i2.2643

[26] D. F. Donnelly and A. Hume, "Using collaborative technology to enhance pre-service teachers' pedagogical content knowledge in Science," Res. Sci. Technol. Educ., vol. 33, no. 1, pp. 61-87, 2015.

DOI:10.1080/02635143.2014.977782

[27] B. Ekiz, A. Tarkin, O. Bektas, M. Tuysuz, E. S. Kutucu, and E. Uzuntiryaki, "Pre-service chemistry teachers' understanding of phase changes and dissolution at macroscopic, symbolic, and microscopic levels," Procedia - Soc. Behav. Sci., vol. 15, pp. 452-455, 2011. DOI:10.1016/j.sbspro.2011.03.120

[28] P. Nilsson and G. Karlsson, "Capturing student teachers' pedagogical content knowledge (PCK) using CoRes and digital technology," Int. J. Sci. Educ., vol. 41, no. 4, pp. 419-447, 2019.

DOI:10.1080/09500693.2018.1551642

[29] B. Yakmaci-Guzel and E. Adadan, "Use of multiple representations in developing preservice chemistry teachers' under-standing of the structure of matter, "Int. J. Environ. Sci. Educ., vol. 8, no. 1, pp. 109-130, 2013. Google Scholar

[30] V. C. Santos and A. Arroio, "The representational levels: Influences and contributions to research in chemical education," J. Turkish Sci. Educ., vol. 13, no. 1, pp. 3-18, 2016.

DOI:10.12973/tused.10153a

[31] D. Milenkovic, D, M. Segedinac, D, and T. Hrin, N, "Increasing High School Students' Chemistry Perfor-mance and Reducing Cognitive Load through an Instructional Strategy Based on the Interaction of Multiple Levels of 
Knowledge Represen-tation," J. Chem. Educ., vol. 91, no. 9, pp. 1409 1416, 2014.

DOI:10.1021/ed400805p

[32] D. F. Treagust, G. Chittleborough, and T. L. Mamiala, "The role of submicroscopic and symbolic representations in chemical explanations," Int. J. Sci. Educ., vol. 25, no. 11, pp. 1353-1368, 2003.

DOI:10.1080/0950069032000070306

[33] H. Barke, G. Harsch, and S. Schmid, Essentials of Chemical Education. Verlag Berlin Heidelberg: springer, 2012.

DOI:10.1007/978-3-642-21756-2

[34] D. Insyasiska, S. Zubaidah, and H. Susilo, "Pengaruh Project Based Learning Terhadap Motivasi Belajar, Kreatifitas, Kemampuan Berpikir Kritis, dan Kemamppuan Kognitif Siswa Pada Pembelajaran Biologi," J. Pendidik. Biol., vol. 7, no. 1, pp. 9-21, 2015.

DOI:10.17977/um052v7i1p9-21
[35] I. R. Lubis and J. Ikhsan, "Pengembangan Media Pembelajaran Kimia Berbasis Android Untuk Meningkatkan Motivasi Belajar Dan Prestasi Kognitif Peserta Didik Sma," J. Inov. Pendidik. IPA, vol. 1, no. 2, p. 191, 2015. DOI:10.21831/jipi.v1i2.7504

[36] N. Supriono and F. Rozi, "Pengembangan Media Pembelajaran Bentuk Molekul Kimia Menggunakan Augmented Reality Berbasis Android," JIPI (Jurnal IIm. Penelit. dan Pembelajaran Inform., vol. 3, no. 1, pp. 53-61, 2018. DOI:10.29100/jipi.v3i1.652

[37] D. Lattisma, W. Kurniawan, S. Seprima, E. Nirbayani, E. Ellizar, and H. Hardeli, "Effect of Chemistry Triangle Oriented Learning Media on Cooperative, Individual and Conventional Method on Chemistry Learning Result Effect of Chemistry Triangle Oriented Learning Media on Cooperative, Individual and Conventional Method on Chemistry Lea," in IOP Conf. Series: Materials Science and Engineering (ICOMSET), 2018, pp. 1-7.

DOI:10.1088/1757-899X/335/1/012103 